\title{
Pleural biopsy in the diagnosis of malignant mesothelioma
}

\author{
AMANDA HERBERT, PATRICK J GALLAGHER \\ From the Department of Pathology, Southampton University General Hospital, Southampton
}

ABSTRACT In an attempt to distinguish reactive from neoplastic mesothelial proliferation, the histological material and clinical records of 153 patients on whom open or closed pleural biopsies were performed during 1976 were reviewed. In six of the 10 patients subsequently shown to have malignant mesothelioma the specimens from closed pleural biopsy had been reported as negative or equivocal but in retrospect showed changes not observed in reactive pleurisy. These included papillary mesothelial proliferation, exfoliated papillae, sheets of atypical mesothelial cells, and abnormal fibroblastic proliferation. In contrast, in inflammatory conditions the mesothelial lining was usually replaced by granulation tissue, although sheets or clumps of exfoliated mesothelial cells were often present in the corresponding pleural fluid clot. Some multilayering of parietal mesothelium was occasionally seen in chronic pleurisy and around metastases.

\section{Introduction}

Although pleural diseases associated with asbestos are relatively common in the community served by the Southampton hospitals we can seldom diagnose malignant mesothelioma confidently from routine closed pleural biopsies. Specimens can be taken only from the parietal pleura and in many cases little tissue is obtained. Furthermore, the biopsy is usually directed for convenience of aspirating pleural fluid rather than for accurate histological sampling. Even in those biopsy specimens where sufficient mesothelial tissue is included the distinction from reactive mesothelial proliferation or secondary carcinoma may be difficult. In addition, cytological examination of pleural fluid aspirates is less reliable in malignant mesothelioma than in metastatic carcinoma. ${ }^{1-4}$ As a result mesothelioma is usually diagnosed at thoracoscopy, thoracotomy, or necropsy, although drill biopsy specimens, in the absence of fluid, may be diagnostic.

In an attempt to establish criteria by which mesothelioma might be suspected in needle biopsy specimens we have reviewed the surgical biopsy material examined in our laboratory in one year. Particular attention was paid to the changes in closed biopsy specimens from patients later shown to have malignant mesothelioma.

\section{Methods}

We reviewed the histological material from 95 men and 58 women who had undergone biopsy during 1976. It

Address for reprint requests: Dr PJ Gallagher, Level E, South Pathology and Laboratory Block, Southampton University General Hospital, Southampton SO9 4XY. included specimens from 95 closed needle or drill biopsies ( 72 patients) and 23 open pleural biopsies or pleurectomies (23 patients) and 158 sections of clots from pleural aspirates (110 patients). The mean age of these patients was 61 years (range 16-87). Where necessary, follow-up information was obtained from the clinical or necropsy records or from the family practitioner.

In some cases additional sections of the pleural biopsy specimens were cut and special stains, such as diastase PAS, Hales colloidal iron, and alcian blue ( $\mathrm{pH} 1.0$ and $2 \cdot 5$ ), with and without hyaluronidase, were used.

\section{Results}

HISTOLOGICAL CHANGES IN CLOSED PLEURAL BIOPSY SPECIMENS

The majority of closed biopsy specimens were obtained with an Abram's needle after aspiration of pleural fluid. In a small proportion a drill biopsy technique was used. The histological diagnoses made from these specimens are summarised in table 1 . In almost half ( 43 biopsies) only skeletal muscle, adipose tissue, or fibrin was retrieved and

Table 1 Diagnoses made on specimens from 95 closed pleural biopsies in 1976

\begin{tabular}{lll}
\hline Diagnosis & $\begin{array}{l}\text { Noof } \\
\text { biopsies }\end{array}$ & $\begin{array}{l}\text { Noof } \\
\text { patients }\end{array}$ \\
\hline Nomesothelium present & 73 & 53 \\
Fibrous pleurisy & 15 & 14 \\
Pus & 4 & 4 \\
?Tuberculosis & 5 & 3 \\
Secondary carcinoma & 6 & 6 \\
No diagnosis & 43 & 26 \\
Reactive or neoplastic mesothelium* & 22 & 19 \\
\hline
\end{tabular}

*See table 2 and text for details. 
the biopsy was of no diagnostic value. In a further 30 biopsies no mesothelial tissue was included but metastatic carcinoma, acute inflammatory cell infiltration, tuberculous granulation tissue, or fibrous pleurisy allowed a pathological diagnosis to be established, or at least suggested. The histological features of the remaining 22 biopsy specimens, which included mesothelial tissue, are detailed in table 2.

Table 2 Histological diagnoses made on specimens from 22 closed biopsies that included mesothelial cells

\begin{tabular}{ll}
\hline & $\begin{array}{l}\text { Noof } \\
\text { specimens }\end{array}$ \\
\hline Reactive & 2 \\
$\quad \begin{array}{l}\text { Single layer mesothelial cells } \\
\text { Exfoliated mesothelial cells }\end{array}$ & 4 \\
$\begin{array}{l}\text { Fibrous pleurisy with hyperplastic } \\
\text { mesothelial cells (three patients) }\end{array}$ & 5 \\
$\begin{array}{l}\text { Metastatic carcinoma with } \\
\text { hyperplastic mesothelial cells }\end{array}$ & 4 \\
$\begin{array}{l}\text { Neoplastic } \\
\text { Papillary proliferation }\end{array}$ & 3 \\
Haphazard fibroblastic proliferation & 2 \\
Solid malignant exfoliated cells (one patient) & 2 \\
\hline
\end{tabular}

In cases of reactive pleurisy mesothelial cells were present either as a monolayer or in non-cohesive exfoliated clumps in close association with the underlying pleural connective tissue. In some areas in which active fibrous organisation was in progress nests of plump multilayered mesothelial cells were in close contact with the pleural surface of the sample. The biopsy specimens that provided the most diagnostic difficulty were from the four patients with reactive mesothelial and carcinoma cells. The malignant cells were either embedded in florid disorganised granulation tissue or closely associated with multilayered clumps of hyperplastic mesothelial cells. In some cases it was difficult to distinguish individual carcinoma from reactive pleural cells.

Seven biopsy specimens (from six patients) showed mesothelial proliferative changes which we felt, in retrospect, must be regarded as neoplastic. Five of these six patients had subsequent histological confirmation of mesothelioma at thoracotomy or necropsy, and the sixth had a history strongly suggestive of mesothelioma although he died without further investigation. These changes were:

(I) Papillary proliferation of mesothelial cells (three patients: figs 1-3) - In one patient invasive papillary tumour was present in a directed drill biopsy specimen and this was reported at the time as probable mesothelioma (fig 3 ). In the other two cases unequivocal papillary processes were identified. These were covered by mesothelium and had definite connective tissue cores. No unquestionable invasion into the underlying fibrous tissue was shown.

(2) Haphazard fibroblastic proliferation (two patients: figs 4 and 5) - In these biopsy specimens the fibroblastic tissue lacked the surface polarisation and vascularity of

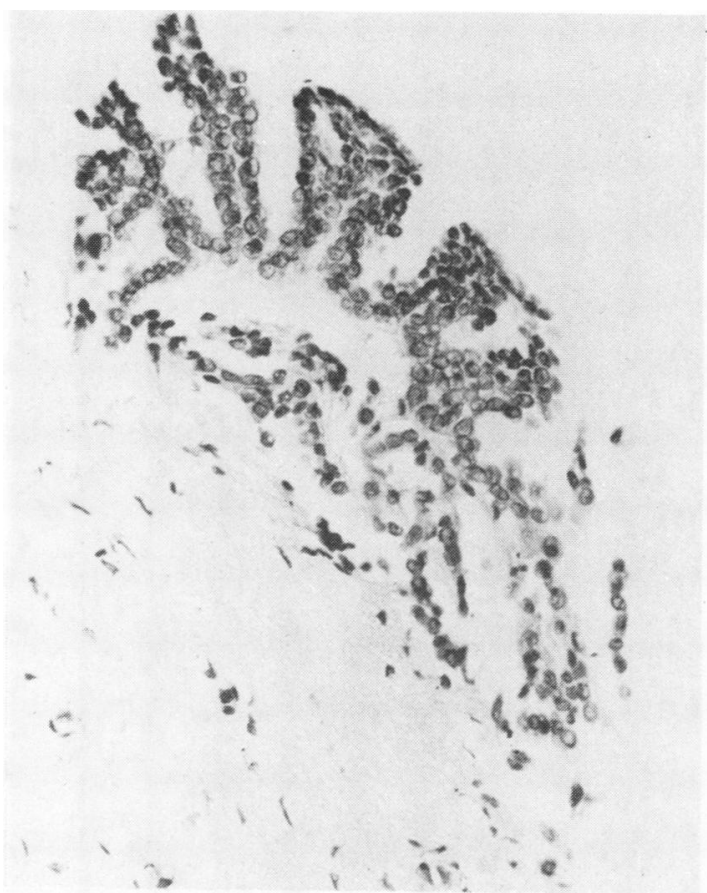

Fig 1 Papillary mesothelial proliferation in a needle biopsy specimen of the pleura. Note connective tissue core in the broadest papilla. ( $H$ and $E \times 400)$

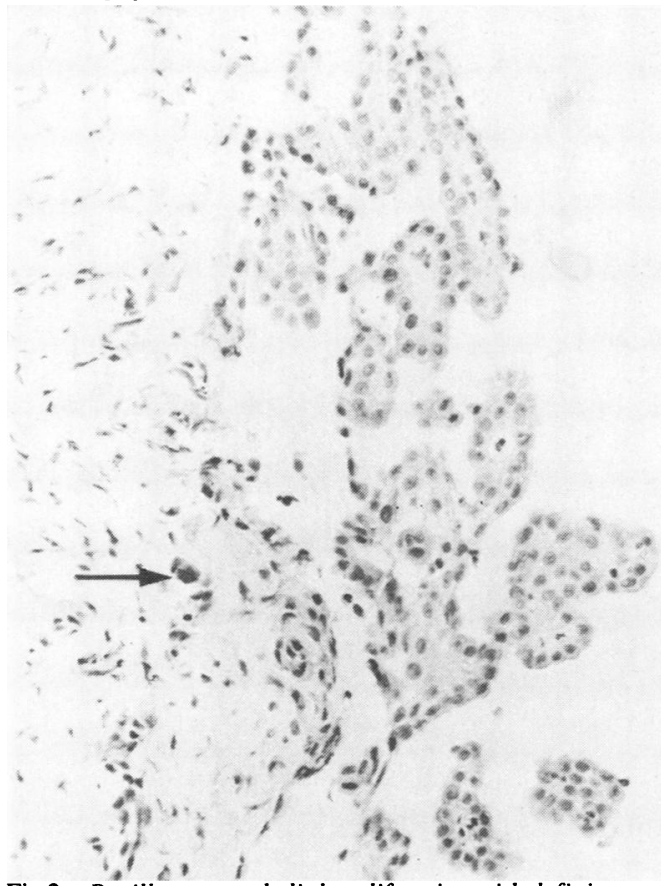

Fig 2 Papillary mesothelial proliferation with definite connective tissue cores and possible focal invasion of underlying pleural fibrous tissue (arrow). ( $H$ and $E \times 400$ ) 


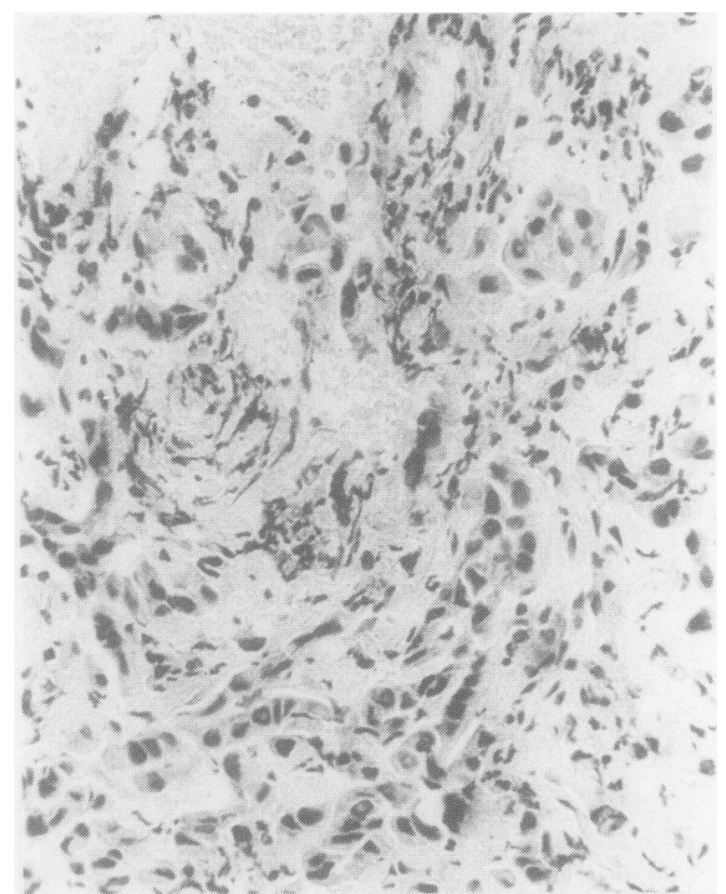

Fig 3 Invasive groups of mesothelial cells in a directed drill biopsy specimen. ( $H$ and $E \times 340)$

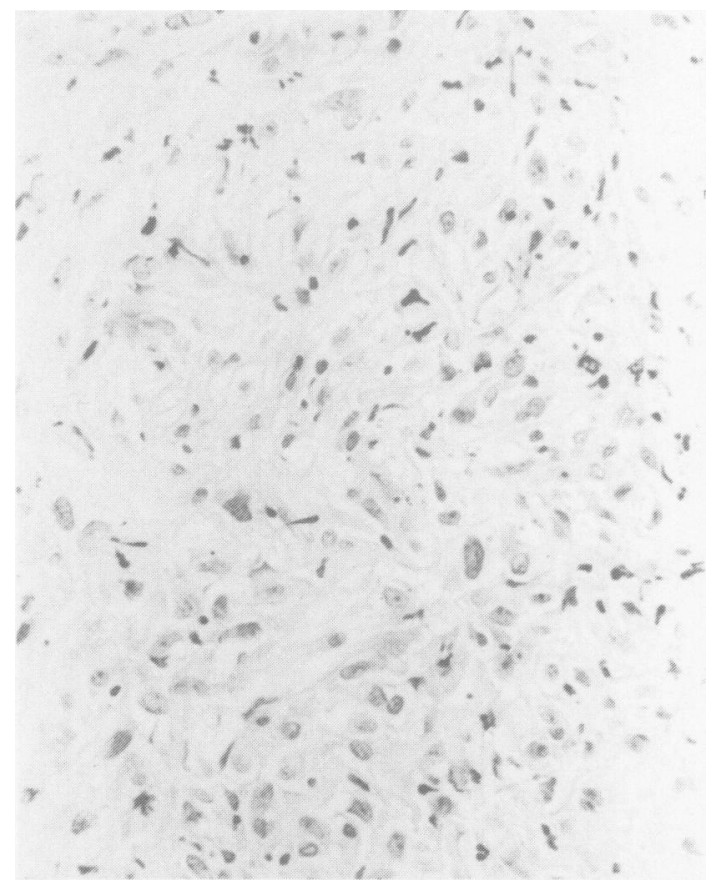

Fig 5 Haphazard fibroblastic proliferation in a closed needle biopsy specimen, with moderate nuclear pleomorphism. (H and $E \times 500$ )



Fig 4 Haphazard fibroblastic proliferation in a closed needle biopsy specimen, with only slight nuclear pleomorphism. (H and $E \times 450$ )

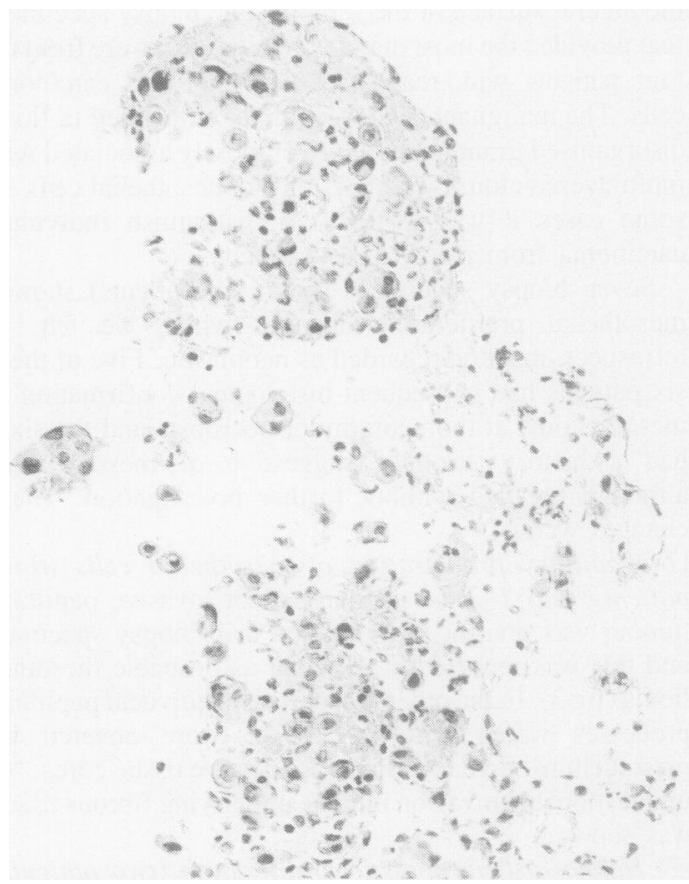

Fig 6 Groups of cohesive pleomorphic mesothelial cells in a closed needle biopsy specimen. ( $H$ and $E \times 540$ ) 


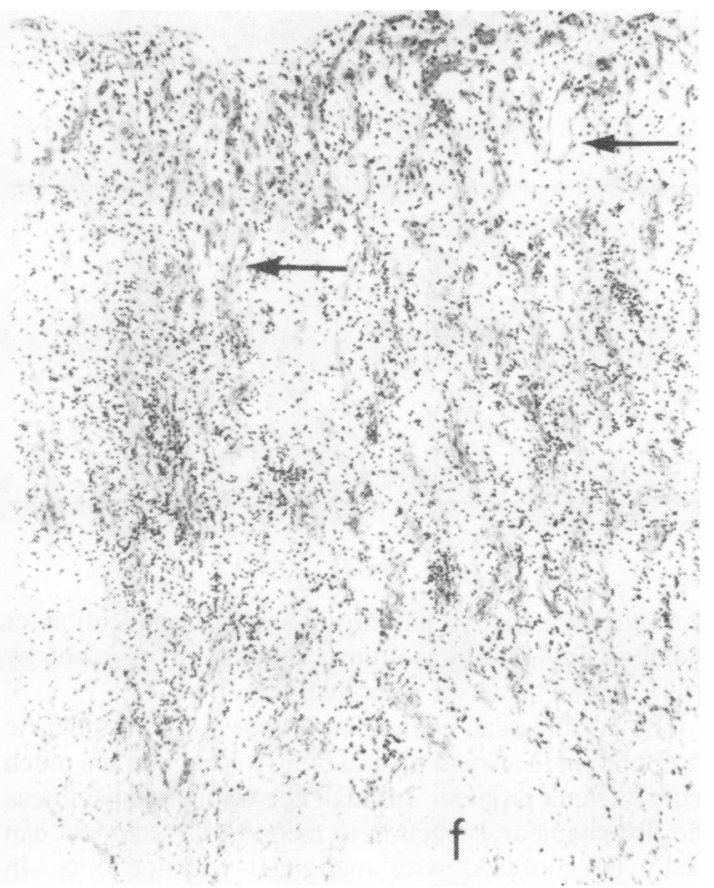

Fig 7 Reactive pleurisy in an open biopsy specimen. The surface mesothelium has been lost. Note plentiful inflammatory cells and prominent capillaries of the granulation tissue (arrow). Underlying pleural fibrous tissue is marked " $f$ ". ( $H$ and $E \times 105$ )

granulation tissue. In one case the mitotic rate was high and in retrospect a diagnosis of malignant mesothelioma could have been made. In the other (fig 4) an objective distinction from florid organising fibrous pleurisy was more difficult but subsequent histological examination confirmed that the lesion was indeed mesothelioma.

(3) Solid exfoliated malignant mesothelial cells (one patient: fig 6) - In this patient sheets of cytologically malignant cells, strongly resembling exfoliated mesothelium, were present in specimens from two consecutive biopsies. Although an equivocal report was issued at the time of biopsy the appearances were sufficiently abnormal to warrant further investigation.

\section{HISTOLOGICAL CHANGES IN OPEN BIOPSY AND DECORTICATION SPECIMENS}

The diagnoses made from open pleural biopsies are summarised in table 3 . In tuberculous and nontuberculous empyemas and non-specific fibrous pleurisy the mesothelial lining was almost always absent. In these cases there was a superficial inflammatory infiltrate, including macrophages and occasional giant cells and an underlying layer of vascular granulation tissue in which capillary loops were arranged perpendicular to the pleural surface (fig 7). In three patients in whom decortication
Table 3 Histological diagnoses made on specimens from 23 open pleural biopsies or pleurectomies in 1976

\begin{tabular}{ll}
\hline Diagnosis & $\begin{array}{l}\text { Noof } \\
\text { patients }\end{array}$ \\
\hline Empyema or fibrous pleurisy or both & 10 \\
Pneumothorax & 3 \\
Talc granuloma & 1 \\
Secondary carcinoma & 3 \\
Mesothelioma & 4 \\
Carcinoma or mesothelioma & 2 \\
\hline
\end{tabular}

was performed for recurrent pneumothorax the characteristic changes of eosinophilic pleuritis were present. ${ }^{5}$

In eight patients an unequivocal diagnosis of neoplasm was made, secondary carcinoma in three and mesothelioma in a further three. Two of these (table 4) were originally reported as probable carcinomas. On review both had a biphasic histological pattern and one prominent intracellular deposit of mucopolysaccharide rich in hyaluronic acid. They can therefore be regarded as cases of malignant mesothelioma. ${ }^{6}$ One patient (No 4, table 4) had an open biopsy shortly before death that showed only fibrous pleurisy. Malignant mesothelioma was found at necropsy, emphasising that these two conditions can co-exist.

\section{HISTOLOGICAL FEATURES OF SECTIONS OF} PLEURAL FLUID CLOTS

A firm diagnosis of neoplasia was made in $20 \%$ of pleural fluid clots (table 5) as opposed to $14 \%$ of needle biopsy specimens (table 1). Six cases were reported as equivocally malignant and on review, even with the benefit of clinical follow-up, a positive diagnosis of carcinoma could not be made. In sections of clots malignant cells often form a separate population, frequently assuming acinar or papillary configurations. Two clots were examined from patients subsequently shown to have mesothelioma at necropsy (table 4). In one the diagnosis had been suggested in the original report but the papillary and acinar structures were very like those seen in carcinomatous effusions. In the other the clumps of cells, although forming papillary clusters, were cytologically benign.

\section{Discussion}

The object of the present study was to compare the histological changes in reactive pleurisy and malignant pleural effusions with those seen in patients later found to have malignant mesothelioma. We hoped that in this way criteria could be developed by which mesothelioma might be suspected in needle biopsy specimens, and an early definitive diagnosis established by subsequent thoracoscopy or thoracotomy. This is of increasing importance in centres where pleuropneumonectomy is available for patients with mesothelioma as this procedure can be 
Table 4 Diagnostic procedures in patients (all men) with mesothelioma*

\begin{tabular}{|c|c|c|c|c|c|}
\hline \multirow{2}{*}{$\begin{array}{l}\text { Case } \\
\text { No }\end{array}$} & \multirow[t]{2}{*}{ Age } & \multicolumn{4}{|c|}{ Histological diagnosis } \\
\hline & & $\begin{array}{l}\text { Pleuralfluid } \\
\text { clot }\end{array}$ & $\begin{array}{l}\text { Closed needle } \\
\text { biopsy }\end{array}$ & Drill biopsy & Open biopsy \\
\hline 1 & 70 & \multirow{10}{*}{ ?Mesothelioma ${ }^{\dagger}$} & & \multirow{9}{*}{ ? Mesothelioma ${ }^{\dagger}$} & \\
\hline 2 & 60 & & Negative ${ }^{\dagger}$ & & Mesothelioma \\
\hline 3 & 68 & & Negative ${ }^{\dagger}$ & & \\
\hline 4 & 61 & & & & Pleural fibrosis \\
\hline 5 & 54 & & & & Mesothelioma \\
\hline 6 & 60 & & & & $\begin{array}{l}\text { Probably carcinoma } \\
\text { ?Mesothelioma } \ddagger\end{array}$ \\
\hline 7 & 64 & & Negative ${ }^{\dagger}$ & & $\begin{array}{l}\text { Probably carcinoma } \\
\text { ?Mesothelioma } \neq\end{array}$ \\
\hline 8 & 68 & & Negative $†$ & & Mesothelioma \\
\hline 9 & 70 & & & & Mesothelioma \\
\hline 10 & 59 & & Negative & ?Mesothelioma $\dagger$ & \\
\hline
\end{tabular}

*Found at necropsy in all cases except Nos 6 (patient still alive) and 11 (no necropsy performed).

$\dagger$ Abnormalities in retrospect suggest mesothelioma.

$\ddagger$ Histology favours mesothelioma in retrospect (see text).

Table 5 Diagnoses made on 158 clotted pleural fluid aspirates in 1976

\begin{tabular}{lcc}
\hline Diagnosis & $\begin{array}{l}\text { Noof } \\
\text { biopsies }\end{array}$ & $\begin{array}{l}\text { Noof } \\
\text { patients }\end{array}$ \\
\hline Carcinoma & 30 & 24 \\
Mesothelioma & 2 & 1 \\
Equivocal malignancy & 6 & 4 \\
Negative & 120 & 81 \\
\hline
\end{tabular}

contemplated only if the diagnosis is made in the early stages of the disease.

We agree with others that needle biopsy of the pleura is seldom diagnostic in malignant mesothelioma, ${ }^{78}$ and that cytological evaluation of pleural fluid (or, as in this study, sections of clots from aspirated fluid) is less reliable for mesothelioma than for metastatic carcinoma. ${ }^{1-4}$ Our study has shown that mesothelial cells are present in only a minority of needle biopsy specimens (table 1), although they are frequently seen in large numbers as exfoliated cells in pleural fluid. In chronic fibrous pleurisy a monolayer, and occasionally a multilayer, of mesothelial cells may be present on the parietal pleura. In the absence of malignant mesothelioma, however, we failed to identify any case in which there was papillary proliferation of surface mesothelioma. Furthermore, in a previous detailed examination of the visceral and parietal pleura in 100 unselected necropsies $^{9}$ we found no evidence of true papillary mesothelial hyperplasia, although finger-like projections of fibrous granulation tissue were occasionally seen in and around areas of pleural fibrosis. Others have reported that mesothelial hyperplasia is common in specimens from biopsies preceding the diagnosis of mesothelioma ${ }^{10}$; but it is emphasised that papillary proliferation of mesothelioma has been described in hernial sacs, ${ }^{11}$ and cystic hyperplasia of the peritoneal mesothelium has been confused with ovarian cystadenocarcinoma. ${ }^{12}$ From this evidence we conclude that the finding of papillary structures in the pleura with definite connective tissue cores is a positive indication for thoracoscopy or thoracotomy, although it may not by itself be diagnostic of mesothelioma.

The histological evaluation of atypical fibroblastic proliferation in a small pleural biopsy specimen is a much more difficult problem. In small needle biopsy specimens the fibrous pleural reaction to metastatic carcinoma can easily be confused with malignant mesothelioma. In inflammatory pleurisy, however, the histological pattern is predictable. The mesothelium is usually replaced by a superficial inflammatory exudate, the intermediate layer is composed of vascular granulation tissue, and there are underlying bands of connective tissue orientated parallel to the pleural surface. In contrast, the collagen and fibroblasts in malignant mesothelioma are haphazardly arranged and granulation tissue is usually absent (figs 4 , 5 , and 7). Although atypical fibroblastic proliferation can seldom be diagnostic of malignant mesothelioma, in our view it should be an additional indication for further investigation.

It is well established that exfoliated mesothelial cells, whether seen in sections of biopsy specimens and clots or in cytological preparations, may assume an atypical, or pleomorphic, cytological appearance. These changes make the distinction between malignant and exfoliated mesothelial cells notoriously difficult. In the present study both malignant mesothelioma and metastatic carcinoma could produce very similar acinar and papillary structures in pleural fluid clots.

An understanding of the histopathology of reactive pleurisy is essential for interpretation of minor change in small biopsy specimens. In particular, we have emphasised the fact that mesothelial cells normally exfoliate in reactive processes and that true proliferative changes are unusual. The changes described here in biopsy specimens from patients who later proved to have malignant mesothelioma were sometimes insufficient for a definitive diagnosis. Such changes could, however, be regarded as indications for thoracoscopy or thoracotomy so that 
repeated and often unhelpful closed biopsies could be avoided.

We thank the Southampton pathologists and pulmonary physicians for access to their histological material and clinical records, Karen Britten and Mary Judd for the illustrations, and Margaret Harris for typing the manuscript.

\section{References}

${ }^{1}$ Naylor B. The exfoliative cytology of diffuse malignant mesothelioma. J Pathol Bacteriol 1963;86:293-8.

${ }^{2}$ Roberts GH, Campbell GM. Exfoliative cytology of diffuse mesothelioma. J Clin Pathol 1972;25:577-82.

${ }^{3}$ Tao LC. The cytopathology of mesothelioma. Acta Cytol 1979;23:209-13.

${ }^{4}$ Frist B, Kahan AV, Koss LG. Comparison of the diagnostic values of biopsies of the pleura and cytologic evaluations of pleural fluids. Am J Clin Pathol 1979;72:48-51.

${ }^{5}$ Askin FB, McCann BG, Kuhn C. Reactive eosinophilic pleuritis. Arch Pathol Lab Med 1977;101:187-91.

${ }^{6}$ Capler D, Eggleston JC. Tumours of the lower respiratory tract. Washington DC: Armed Forces Institute of Pathology, 1980:328-51.

${ }^{7}$ Whitwell F, Rawcliffe RM. Diffuse malignant pleural mesothelial and asbestos exposure. Thorax 1971;26:6-22.

${ }^{8}$ Kannerstein M, Churg J, McCaughey WTE. Asbestos and mesothelioma: a review. Pathology Annual 1978; 13 (part 1): 81-129.

${ }^{9}$ Sheldon CD, Herbert A, Gallagher PJ. Reactive mesothelial proliferation. A necropsy study. Thorax 1981;36:901-5.

${ }^{10} \mathrm{Klima} \mathrm{M}$, Cyorkey F. Benign pleural lesions and malignant mesothelioma. Virchows Arch Series A 1977;376: 181-93.

${ }^{11}$ Rosai J, Dehner LP. Nodular mesothelial hyperplasia in hernia sacs. A benign reactive condition simulating a neoplastic process. Cancer 1975;35:165-75.

12 Jacobson ES. Benign papillary peritoneal cystosis simulating serous cystadenocarcinoma of the ovary. Am J Obstet Gynecol 1974;118:575-6. 